\title{
Vivência da mulher na escolha do Método de Ovulação Billings
}

\author{
Woman's experience with the choice of the Billings Ovulation Method \\ Experiencia de la mujer en la elección del Método de Ovulación Billings
}

\section{Adriana Cristina de Magalhães', Daliane da Silva Alves Pereira', Danúbia Mariane Barbosa Jardim", Michelle Caillaux', Vinícius Bernardo Lemos Sales'}

\author{
' União de Negócios e Administração, Centro Universitário de Ciências Gerenciais, \\ Curso de Graduação em Enfermagem. Belo Horizonte-MG, Brasil. \\ "Hospital Sofia Feldman. Belo Horizonte-MG, Brasil.
}

Submissão: 02-08-2011 Aprovação: 01-07-2013

\section{RESUMO}

Trata-se de um estudo de caso com abordagem qualitativa, realizado entre fevereiro e novembro de 2010, com 10 mulheres, com idade média de 34 anos, usuárias do Método da Ovulação Billings (MOB), há mais de dois anos, cujo objetivo foi compreender a vivência da mulher na escolha do MOB. Os dados foram obtidos a partir de entrevistas, e analisados segundo a técnica de análise de conteúdo. As categorias de análise apontaram as principais influências na escolha do MOB: religião; naturalidade do método e benefícios do autoconhecimento. Concluiu-se que as mulheres revelam confiança na realização do método, que ele traz benefícios para as usuárias e que há necessidade de orientação profissional para a sua prática correta.

Descritores: Métodos Naturais de Contracepção; Planejamento Familiar; Saúde da Mulher.

\section{ABSTRACT}

This is a case study with a qualitative approach, carried out between February and November 2010 with 10 women, mean age of 34 years old, users of this Billings Ovulation Method (MOB) for over than two years, with the objective of understand the experience of women by choosing the MOB. Data was obtained from interviews, and analyzed through content analysis technique. The categories of analysis showed that the reasons for the choices of the MOB were: religion; natural method, and benefits of self-knowledge. It was concluded that women show confidence in carrying out the method, that it brings benefits for users and that there is a need for professional guidance for its correct practice.

Key words: Natural Family Planning Methods; Family Planning (Public Health); Women's Health.

\section{RESUMEN}

Se trata de un estudio de caso con abordaje cualitativa, realizado entre febrero y noviembre de 2010, con 10 mujeres, con edad media de 34 años, usuarias del Método de la Ovulación Billings (MOB) a más de dos años, cuyo objetivo fue comprender la vivencia de la mujer en elegir el MOB. Los dados se obtuvieron a partir de entrevistas, y fueran analizados según la técnica de análisis de contenido. Las categorías de análisis mostraron que las mayores influencias para la elección del MOB fueron: religión; naturalidad del método y beneficios del auto-conocimiento. Sin embargo, se concluye que las mujeres muestran confianza en la realización del método, que esto trae beneficios para ellas y que hay necesidad de orientación profesional para la práctica correcta del método.

Palabras clave: Métodos Naturales de Planificación Familiar; Planificación Familiar; Salud de la Mujer. 


\section{INTRODUÇÃO}

Na história dos métodos contraceptivos, vários documentos mostram a utilização de ervas, substâncias ácidas e unguentos, nas condutas para anticoncepção realizadas por civilizações antigas. Desde os séculos XVIII e XIX a.C., os egípcios mencionavam em papiros a composição de tampões vaginais, compostos de goma de acácia, mel e até fezes de crocodilo que, segundo eles, impediam a concepção ${ }^{(1)}$. Os documentos com registro científico sobre a temática surgiram no século XVI, na Europa, a partir da introdução e difusão das artes, da ciência e dos estudos filosóficos, que levaram a novos conhecimentos da anatomia e da fisiologia do sistema reprodutor feminino ${ }^{(2)}$. Grandes avanços na medicina e especificamente na área da ginecologia aconteceram nos séculos XIX e XX, culminando com a criação de diferentes métodos de contracepção e a utilização em larga escala pela população feminina e masculina(3). Na década de 60, vários fatos marcaram as discussões sobre planejamento familiar no âmbito mundial, e as estratégias para sua implantação efetiva, dentre eles, a Conferência Internacional de Teerã, realizada em 1968, comemorando o $20^{\circ}$ aniversário dos Direitos Humanos da ONU, onde 84 países foram unânimes em aceitar o planejamento familiar como um direito humano fundamental e universal ${ }^{(4)}$.

No Brasil, até a década de 70, as políticas de saúde da mulher eram direcionadas apenas para o período gravídico-puerperal. Nesse período, o Ministério da Saúde, Previdência e Assistência Social, precursor do atual Ministério da Saúde, articulou algumas propostas à população quanto ao planejamento familiar, pois o país apresentava altos índices de natalidade. Somente a partir da década de 80, a anticoncepção teve respaldo, através da promulgação da nova Constituição Federal ${ }^{(5)}$. Atualmente, mais de cem mil mulheres em todo o mundo utilizam algum contraceptivo oral. Uma pesquisa feita pela Federação Brasileira das Associações de Ginecologia e Obstetrícia, em cinco capitais, Recife, Rio de Janeiro, Porto Alegre, São Paulo e Belo Horizonte, revela que $84 \%$ das muIheres entrevistadas, que utilizam algum contraceptivo oral, decidiram troca-lo, pois se queixaram de dores de cabeça, enjoo e, principalmente, aumento de peso ${ }^{(6)}$.

Apesar de uma grande soma de dinheiro ter sido investida no desenvolvimento e aprimoramento de métodos químicos e mecânicos de anticoncepção, muitos produtos, como a pílula e o diafragma, por exemplo, possuem alto índice de efeitos colaterais e insucesso em sua utilização ${ }^{(6-7)}$. Mulheres que buscam novas alternativas, menos agressivas ao organismo, têm nos métodos naturais uma opção de controle da fertilidade, como por exemplo, os métodos de ritmo e o da temperatura. Porém, estes têm gerado grande desconfiança ou restrições para o casal, dificultando o seu uso. Conscientes desta lacuna, um grupo de doutores e pesquisadores médicos de Melbourne, na Austrália, desenvolveu, durante 27 anos, um método simples, mas substancial, no qual as mulheres reconhecem períodos férteis ou inférteis a partir das características do muco, que podem ver e sentir no orifício vaginal. A base do método, portanto, é o reconhecimento do muco $^{(8)}$. Este é produzido pela cérvix, e está sob o controle dos hormônios reprodutivos. Além disso, estudos científicos mostraram que o muco é essencial para que ocorra a concepção, como também para demonstrar o estado de fertilidade, através da sensação e aparência, quando ele se mostra presente. No primeiro estudo sobre o muco cervical, Smith (1855) descreve que a concepção tem a maior possibilidade de ocorrer quando o muco está "na condição mais fluida"(8), Para os autores Seguy e Simmonet (1933), o muco apresentado pela mulher no momento fértil tem relação com o ápice de produção de estrógeno(8). Após o acompanhamento de centenas de mulheres, John Billings (1953) constatou que a sensação produzida pelo muco, assim como sua aparência, serviu para que elas reconhecessem o inicio da fertilidade ${ }^{(8)}$. Na década de 1970, o estudo de Billings passa a ser cientificamente aceito como um método contraceptivo eficaz, após informe preliminar com indicação de 97\% de eficácia. Estudo randomizado, realizado em mulheres usuárias do Método da Ovulação Billings (MOB), em vários países de diversos continentes, contribuiu para o abandono do uso de medidas de temperatura e de cálculos de ritmo associados ao MOB, comparando-o favoravelmente com a eficácia de métodos anticoncepcionais conhecidos, como a pílula e o Dispositivo Intrauterino (DIU) ${ }^{(8)}$.

Diante da necessidade de controle da concepção, o enfermeiro, assim como os demais profissionais de saúde, deve conhecer os métodos contraceptivos, com o intuito de informar e instruir as usuárias que desejam - ou precisam - utilizar métodos que fogem aos parâmetros tradicionais - químicos e mecânicos - ou que, por algum motivo estão impedidas de fazer seu uso, garantido ao casal o direito pregado pela constituição federal de planejamento familiar responsável ${ }^{(5)}$.

A oposição ao método advém, principalmente, dos que o confundiram com o método de ritmo, ou dos que não receberam a informação correta para executá-lo, sendo assim, a possibilidade de insucesso na sua utilização é alta, atribuindo ao MOB um falso caráter de ineficaz. Vale ressaltar que por ser um método comportamental, ele requer um empenho do casal, para que juntos consigam chegar ao objetivo da anticoncepção.

Para realizar este estudo, ainda com base no que foi acima citado, os autores foram norteados pelas seguintes inquietações: porque as mulheres escolhem o Método da Ovulação Billings? Como elas o executam? As usuárias confiam neste método? Pensando assim, o estudo teve como objetivo central compreender a percepção da mulher na escolha do método da ovulação Billings e, como objetivos específicos, descobrir o porquê de sua escolha por esse método; além de avaliar seu conhecimento durante sua realização.

\section{PERCURSO METODOLÓGICO}

Realizou-se um estudo de caso descritivo e exploratório com abordagem qualitativa, no período entre fevereiro e novembro de 2010, buscando alcançar os objetivos propostos pelo trabalho. A população do estudo foi estabelecida durante a coleta de dados sendo utilizado o critério de saturação, ou seja, quando as informações se tornaram repetitivas, pôde-se 
considerar o número de participantes suficiente ${ }^{(9)}$. Foram entrevistadas 10 mulheres na faixa etária média de 34 anos, que utilizavam exclusivamente o Método da Ovulação Billings, há no mínimo dois anos, com a finalidade de contracepção e/ ou fertilidade; e que já possuíam experiências anteriores com outros métodos contraceptivos. Estes sujeitos do estudo foram obtidos por contato direto com os pesquisadores e através de informantes, os que concordaram em participar leram e assinaram o termo de consentimento livre e esclarecido. Ressalta-se que foi resguardado o anonimato dos informantes e que o estudo obteve aprovação do Comitê de Ética em Pesquisa (CEP), do Centro Universitário UNA, conforme o protocolo 28/2010 e registro no Ministério da Saúde sob o Sisnep número: 0015.0.391.000-10.

Como estratégia de coleta de dados, utilizou-se a técnica de entrevista semiestruturada, estas foram gravadas e transcritas na íntegra, para posterior análise. Os dados obtidos foram organizados segundo a Técnica de Análise Conteúdo(10), seguindo as seguintes etapas: $1^{\circ}$ a pré-análise; $2^{\circ}$ a exploração do material e; $3^{\circ}$ o tratamento dos resultados, a inferência e a interpretação. Na pré-análise, os dados foram ordenados, transcrevendo as entrevistas de forma integral e preservando as falas na íntegra ${ }^{(10)}$. Posteriormente, o material transcrito foi agrupado, submetido a uma análise detalhada e exaustiva e confrontado com a literatura encontrada. O resultado disso foram núcleos de sentido, que acarretaram a concretização dos subtemas deste estudo e a construção de três categorias: Método Billings: o porquê de sua escolha; do conhecimento à prática; do medo à segurança.

\section{RESULTADOS E DISCUSSÃO}

\section{Perfil das Mulheres}

O perfil dos sujeitos da pesquisa, a partir dos dados levantados durante as entrevistas, está apresentado na tabela abaixo:
A partir de uma breve análise, verifica-se a unanimidade $(100 \%)$ sobre o estado civil das participantes (casadas), ressaltando a importância da estabilidade na relação para a realização do método, mesmo este não sendo um parâmetro de exclusão para a sua utilização. A idade média das participantes e o tempo médio de uso do método são, respectivamente, de 34 e 7, 7 anos. Quanto ao grau de escolaridade, nota-se uma parcela significativa com mais de 15 anos de estudo (80\%), apesar de o nível de escolaridade também não ser fator determinante para a realização do método.

\section{Método Billings: o porquê da escolha}

A escolha de um método contraceptivo pelo casal é permeada por diferentes aspectos, como aceitação física, habilidade em seu manejo, entendimento do usuário, fatores sócio-culturais, dentre outros. Estes diversos aspectos podem influenciar de maneira positiva ou negativa, o que não podemos é menosprezar sua existência, nem tampouco negar que estes são marcadores na construção de um planejamento familiar seguro e eficaz. Na opção pelo método Billings, várias influências foram citadas pelas mulheres entrevistadas. A religião foi o fator principal para escolha deste método.

Eu estava procurando um método natural, por usar o anticoncepcional e não me adaptar, e também, o conhecimento da palavra e por questões religiosas. (E1)

Primeiramente por causa da questão religiosa, da Igreja aceitar o método, para espaçamento entre os filhos. (E6)

Porque é um método permitido pela Igreja. (E7)

A religião como motivação para realização do método esteve presente em metade das entrevistas realizadas. A importância das religiões na vida das pessoas é indiscutível. A sexualidade

Tabela 1 - Perfil das mulheres entrevistadas. Belo Horizonte-MG, 2010.

\begin{tabular}{|c|c|c|c|c|c|}
\hline Entrevista & Estado civil & Idade (anos) & Profissão & $\begin{array}{c}\text { Tempo de Método } \\
\text { Billings (anos) }\end{array}$ & Escolaridade \\
\hline 1 & Casada & 36 & Pedagoga & 6 & Superior \\
\hline 2 & Casada & 32 & Comerciante & 10 & Superior \\
\hline 3 & Casada & 28 & Assit. de Rh & 3 & Médio \\
\hline 4 & Casada & 28 & Enfermeira & 3 & Superior \\
\hline 5 & Casada & 29 & Enfermeira & 4 & Superior \\
\hline 6 & Casada & 37 & Professora & 11 & Superior \\
\hline 7 & Casada & 38 & Do lar & 3 & Médio \\
\hline 8 & Casada & 29 & Odontóloga & 2 & Superior \\
\hline 9 & Casada & 35 & Geógrafa & 15 & Superior \\
\hline 10 & Casada & 57 & Médica & 20 & Superior \\
\hline Total: 10 & Total: 10 & $\begin{array}{l}\text { Média: } \\
\text { 34,9 anos }\end{array}$ & & $\begin{array}{l}\text { Média: } \\
\text { 7,7 anos }\end{array}$ & $\begin{array}{l}\text { Total: } 3^{\circ} \text { Grau } 8 \\
\text { Total: } 2^{\circ} \text { Grau: } 2\end{array}$ \\
\hline
\end{tabular}


é parte da vida cotidiana de todos os seres humanos e é um tema abordado de maneira muito diferente entre as diversas religiões. Algumas doutrinas pregam que o controle da natalidade deve ser realizado de maneira natural e espontânea, já que o princípio básico descrito nas escrituras é que cresçamos e multipliquemos. Assim, qualquer que seja a religião, ela exerce forte influência sobre a sexualidade e o comportamento das pessoas $^{(11)}$. O método Billings também foi escolhido pelas entrevistadas diante de sua não adaptação a métodos escolhidos anteriormente.

Eu já utilizei a pílula, e pra mim era horrível, porque eu tinha muito enjôo, muita cólica, e eu não me adaptei (...) por isso eu estava em busca de outro método... (E1)

Durante um período eu utilizei o Mirena (DIU) que é um método contraceptivo interno, não me sentia confortável com esse método (...) apesar de ser um dos métodos mais seguros e um dos métodos que hoje mais modernos de poder se evitar a gravidez (...) eu não me sentia confortável com utilização desse método... (E3)

"Eu já utilizei a pílula, e não me sentia bem, devido a inchaço, mal estar, enjoo..." (E4)

Já utilizei o método de barreira, a camisinha. Não me adaptei. E o anticoncepcional oral (...) também não me adaptei. (E5)

Já utilizei anticoncepcional eu me sentia muito mal, tinha enxaqueca, dor nas pernas (...). Eu tinha aquele sangramento chamado "splot" durante o ciclo menstrual (...) eu não me sentia bem. (E8)

A escolha do método Billings, na maioria das vezes, se sucede a outras tentativas de contracepção, como os métodos de barreiras e hormonais. A não adaptação com os métodos anteriores e seus efeitos colaterais: inchaço, enjôo, náuseas, desconforto, enxaqueca e dor, levam as mulheres a continuarem na busca por um método contraceptivo que proporcione bem-estar e conforto. Assim o Método Billings aparece como uma tentativa para obter sucesso no planejamento familiar, sem agressão ao corpo ou sacrifícios adicionais que outros métodos acarretam ${ }^{(8)}$. A escolha pelo MOB acontece também a partir de uma inquietação pessoal em busca de um método melhor para si.

... Conheci uma moça na Federal que fazia enfermagem e fazia o Billings, achei interessante como ela era confiante, em fazer esse método, sem medo da gravidez, desde então comecei a estudar sobre o assunto, para provar para mim se ele era seguro, então comecei a fazer, para testar e não é que deu certo! (E10)

A curiosidade fez com que a mulher buscasse informações para a sua utilização e confirmasse a eficácia de algo estigmatizado - os métodos comportamentais - reafirmando o MOB como método seguro e eficaz, após estudo e orientação. Mais um incentivo deste método é o sentido de admiração e profunda satisfação que provém de estar em sintonia com os ritmos naturais do corpo ${ }^{(12)}$.

... Estar tranquilo comigo mesma, saber que não estou indo contra aquilo que eu acredito. Também porque é um método que respeita minha pessoa, ou seja, não me agride física e psicologicamente, respeita o funcionamento natural do meu corpo (...) É um método onde não tem nada de artificial, muito pelo contrário, você se conhece melhor, respeita sua individualidade, não produz malefícios para sua saúde... (E7)

Optei por ser um método natural, que não agride meu organismo, por acreditar que ele é um método seguro, por me sentir bem na realização do método. (E4)

... Esse método auxilia a mulher a se conhecer, conhecer o próprio corpo, conhecer seus momentos de fertilidade (...) e reconhecer, muitas das vezes o meu temperamento. (E3)

Assim as adeptas pelo método buscam uma alternativa segura e que não agrida, ou atrapalhe o funcionamento natural de seu corpo. Elas procuram obter uma profunda sintonia consigo mesmas e acreditam que assim poderão alcançar o autoconhecimento, capaz de promover o bem estar físico, mental e espiritual. Este conhecimento é transferido para as ações cotidianas, já que o bem-estar por ele proporcionado reflete no surgimento de mulheres seguras, confiantes e que dominam uma situação fundamental em suas vidas: o controle de sua fecundidade.

\section{Método Billings: do conhecimento à prática}

Em nossa sociedade, o método Billings é pouco difundido e aceito pelos usuários. Talvez devido a uma visão equivocada, que o concebe como inseguro e ineficaz, oferecendo muitos riscos para quem o pratica. O que gera esta desconfiança é desconhecimento sobre como é realizado ou, em alguns casos, a sua prática de maneira incorreta. Deste modo, ao longo das entrevistas, percebemos a necessidade das mulheres de nos revelar, em seus discursos, como realizam o método, expresso nos seguintes trechos:

Eu observo a presença do muco (...) mais ou menos no décimo quarto dia do meu do meu período, e ai eu sei que neste dia eu estou ovulando, então eu tenho uma margem de segurança dois dias antes dois dias depois (...) e nesse período eu não tenho relação sexual. (E5)

Com a ovulação os hormônios femininos fazem com que a cérvix produza um tipo de muco, então quando esse muco esta presente, nestes dias, eu evito ter relação sexual (...) no período pré-ovulatório, são alternadas as noites que são possíveis ter relações. Assim que eu identifico o período fértil, eu espero três dias (...) após esses três dias, todos os dias estão liberados para relações sem medo de uma futura gravidez (...) esse muco tem um aspecto escorregadio, de clara de ovo, é um muco distensível, bem característico nesse período ovulatório... (E4) 
... Observando as características do muco cervical, procuro anotar essas observações e saber quando estou entrando no período fértil (...) entrando nessa fase, vejo que o muco é mais claro, mais elástico, se quero evitar uma gravidez entro em abstinência sexual, contando mais três dias. (E7)

... Pela observação do muco, nos dias que percebo que o muco esta mais consistente. É o dia que realmente não pode ter relação (...) eu observo dois dias antes e dois dias depois e evito nesses dois dias também (...) fora isso, relação normal. (E8)

As alterações produzidas pelo muco cervical é que norteiam as mulheres se estão ou não no período fértil. Nos discursos acima encontramos algumas informações confusas, desencontradas, incorretas quanto à realização do método. Para algumas o muco que sinaliza o período fértil é semelhante a uma clara de ovo, e um muco distensível, já para outras o muco que indica fertilidade é de aspecto mais consistente. Outra diferença encontrada nas falas é quanto ao tempo de abstinência sexual durante o período fértil que para algumas é de dois dias antes e depois, já para outras é de três dias.

Para a correta utilização do método, é importante verificar que os primeiros dias inférteis são os dias antes de ocorrer qualquer mudança no padrão básico de infertilidade. Tais dias podem ser secos, sem qualquer sinal de muco, ou mesmo que ele ocorra, será quase seco, pegajoso ou espesso, constante, dia após dia, indicando infertilidade ${ }^{(8,12)}$. Uma mudança nesse padrão indica possível fertilidade. Relações sexuais poderão ocorrer em noites alternadas, apenas nesta fase do ciclo. Se o padrão básico de infertilidade muda em algum aspecto, mesmo que mínimo, é aconselhável que durante esta fase não haja relações sexuais, mantendo uma margem de três dias após a mudança, para verificação se realmente o muco é fértil ou não ${ }^{(8,12)}$. Quando surge uma sensação de lubrificação ou verifica-se o aparecimento do muco claro - ou filamentoso - esse será considerado o dia ápice de fertilidade. Esse dia coincide, de perto, com o dia da ovulação. Caso a mulher utilize o método como contraceptivo, deve-se evitar a relação sexual neste dia e nos outros três consecutivos. Caso ela o utilize como método de fertilidade, este dia, mais os três seguintes são indicados para o coito ${ }^{(8)}$.Os trechos a seguir evidenciam a correta utilização do método:

Após a menstruação os dias inférteis são os dias antes de qualquer mudança, por isso nesse período pré-ovulatório as relações sexuais serão permitidas em dias alternados, para que o líquido seminal e as secreções vaginais não confundam a mulher que observa, qualquer mudança do padrão básico de infertilidade (...) indica uma possível fertilidade (...) se o muco aparece espera-se 3 dias para verificar se o padrão de infertilidade volta, se voltar o período ovulatório já aconteceu (...) se voltar o muco tem que se usar novamente a regra dos 3 dias, e esperar para ver se volta o padrão de infertilidade, que é o marcador da passagem da ovulação. (E10)

Eu observo o muco cervical, presente em forma de clara de ovo, elástico, no período mais fértil, logo após minha menstruação... Fico bem atenta ao primeiro sinal do muco, alternando as noites de relação, quando percebo o muco, conto três dias se desaparecer e voltar a ficar seca é porque a ovulação já foi, e não terei chance de engravidar, se depois de três dias não passar, espero até acabar o muco, para ter certeza, que a ovulação já foi. (E9)

Por se tratar de um método comportamental é fundamental saber corretamente a técnica, para que não haja enganos conseqüentes da prática incorreta e insucesso nos objetivos desejados. Neste momento, a procura de profissionais de saúde ou de pessoas capacitadas para ensinar o método corretamente torna-se fundamental. Deste modo, quando a técnica do MOB é corretamente praticada pelas mulheres, o conhecimento propiciado por seu exercício traz inúmeros benefícios para a mulher. Isto se revela nos trechos abaixo:

... Você passa a conhecer o seu corpo e com isso você pode estar prevenindo contra doenças (...) como já aconteceu comigo, observando no muco eu vi que estava diferente e busquei um médico, e realmente e estava com problema (...) eu acho importante também, você ensinar as suas filhas adolescentes, para que possa conhecer o seu corpo... (E1)

... Eu coloco mais um ponto positivo no método, no conhecimento do ciclo e do corpo, porque através da mudança do meu muco, eu vi aqui alguma coisa estava errada, procurei a ginecologista, e através de exames de imagem, verificou-se mesmo uma patologia, e que foi tratada posteriormente (...) se eu utilizasse algum outro método contraceptivo, não daria pra eu perceber... (E4)

O autoconhecimento propicia ao indivíduo a autonomia e a emancipação, necessárias para cuidar de si e de sua família. Ele está associado ao exame crítico e ao respeito com o corpo, além de melhorar a qualidade de vida, garantindo componentes essenciais da condição humana à mulher, quer seja físico, psicológico, social, cultural ou espiritual ${ }^{(13)}$. O autoconhecimento, proporcionado pela prática do $\mathrm{MOB}$, promove a saúde e responsabilização do indivíduo nesse processo, ao invés de tratar a saúde apenas como ausência de doença, vai de encontro com os princípios pregados pelo SUS, opondo-se à medicalização da vida social e incorporando ao indivíduo valores como solidariedade, cidadania, desenvolvimento, participação e parceria ${ }^{(14-15)}$. Outro benefício trazido pelo método Billings é a flexibilidade e segurança que ele propicia às mulheres, que possuem ciclos irregulares.

Eu olho pelo muco à medida que eu vou observando esse muco eu vou vendo meu período fértil e que não é o meu período fértil (...) Principalmente porque o meu ciclo não é regular (...) então nesse caso a tabelinha não funcionava (...) e o método Billings, ele pra mim foi o ideal. (E1)

Por ser um método observacional, o Billings, atende a qualquer tipo de padrão de fertilidade, mesmo os irregula$\operatorname{res}^{(8)}$, reafirmando sua aplicabilidade em todas as variações da fisiologia reprodutiva da mulher, tanto a normal quanto 
a patológica, assim como em ciclos regulares, irregulares e anovulatórios $^{(16)}$. É importante ressaltar que a utilização do método também reflete na vida do casal, que passa a ter cumplicidade nas decisões quanto ao planejamento familiar.

É um método também que aproxima o casal (...) que os dois fazem juntos (...) os dois podem se conhecer. (E4)

Eu falo que no meu meio de trabalho às vezes as mulheres ficam com medo (...) aí eu falo (...). Se você usar certinho (Método Billings), tiver um marido que compreenda, ele funciona. (E6)

O relacionamento conjugal se torna mais aberto ao diálogo e ao respeito. (E7)

O relato das mulheres evidencia a importância do parceiro na realização do método, tornando-o corresponsável da verificação do estado de fertilidade do casal, e aproximando-o, cada vez mais, de sua parceira, pois passam a tomar decisões em conjunto. Não é vão que a Constituição Federal Brasileira, de 1988 (art.226, § 70), trata a contracepção e a escolha reprodutiva como um direito de mulheres e de homens ${ }^{(5,17)}$, dispondo aos cidadãos, leis que os amparem na escolha de métodos contraceptivos e a assistência para a concepção, em situações de infertilidade ${ }^{(5)}$. Billings (2007), também trata o planejamento familiar como responsabilidade do casal, e que a fertilidade do marido e da esposa são um vínculo especial, uma doação íntima e exclusiva de $\operatorname{ambos}^{(8)}$. O relato a seguir evidencia que, através do conhecimento de seu corpo, torna-se possível aumentar a margem de dias permitidos para relações sexuais, diminuindo o período de abstinência.

... Então assim, já falei (...) às vezes as pessoas ficam meio inseguras, meio "cabrera", acham que não funciona muito (...) à medida que você vai tendo a segurança (...) à medida que você conhece o seu corpo mesmo, você pode arriscar mais, dar mais margem. (E6)

A abstinência sexual é algo temido pelos casais, fato que acaba contribuindo ainda mais para que ocorra uma queda na taxa dos usuários do Método da Ovulação. No entanto, estudo(18) $^{(18 p r e s e n t a ~ q u e, ~ a ~ p a r t i r ~ d o ~ u s o ~ d o ~ m e ́ t o d o, ~ o ~ i ́ n d i c e ~}$ de atividade sexual aumentou entre os casais. Este dado não condiz com o que afirma o senso comum, de que usuários de métodos naturais de planejamento familiar têm as relações sexuais diminuídas, devido à exigência da abstinência periódica. Além dos benefícios para a saúde do corpo da mulher e seu autoconhecimento, o casal passa a conviver com a possibilidade do aumento da atividade sexual ${ }^{(18)}$. Contudo, vale ressalvar que cientificamente a margem de dias, citada pela entrevistada (E6), abre espaço para o risco de o método falhar. É por este motivo que Billings (2007) enfatiza a utilização metódica das regras, para que sua eficácia seja garantida.

\section{Método Billings: do medo à segurança}

O sentimento de medo e insegurança na realização do método Billings geralmente aparece em algum momento da vida das mulheres. Isso ocorre, provavelmente, pelo fato de ser um método que exige da mulher um conhecimento de seu padrão de fertilidade. A verificação deste padrão - bastante influenciado pelo meio externo e estilo de vida de cada mulher - pode tornar-se confusa, impedindo as usuárias de conseguir identificar seu muco com clareza, gerando insegurança.

... Senti-me insegura, porque a característica do muco, às vezes, muda muito. Então eu não conseguia identificar realmente, se era o período ovulatório, a pessoa tem que estar muito ciente das oscilações do nosso corpo, no período ovulatório. (E5)

... Tinha mês que eu não percebia o muco (...) então eu ficava (...) será que eu não ovulei (...) será que eu não percebi? (...) ai eu ficava mais atenta. (E6)

Quanto maior forem as orientações recebidas, de fontes confiáveis, maior será a capacidade da mulher de reconhecer as características dos períodos de seu ciclo. A educação em saúde pregada por Paulo Freire cita que para serem eficazes, as ações devem ser direcionadas às necessidades individuais da pessoa ${ }^{(19)}$. Apropriando das informações trabalhadas, o indivíduo muda seu comportamento. Contudo, quanto mais informações tiverem, mais assumem atitudes responsáveis ${ }^{(19-20)}$. O medo de algo novo faz com que muitos, por não conhecerem o método, sintam insegurança, e fiquem receosos para a prática do mesmo. Outra justificativa para a insegurança da mulher é a falta de treinamento ou acompanhamento durante o inicio da prática do método, desencadeando a incerteza da eficácia do método, o que gera dúvida e receio.

\section{Insegura? No inicio sim (...) Mas hoje é tranqüilo. (E7)}

... Como eu nunca procurei uma orientação específica, faço o método somente pelo o que eu li no site, eu senti um pouco de insegurança (...) me faltou essa segurança por parte de uma pessoa que realmente entenda do método. (E8)

A falta de orientação e a busca em fontes impróprias - sites, revistas ou livros sem fundamentação científica - alimenta a insegurança das mulheres, faz com que o método torne-se potencialmente perigoso e incerto, repleto de lacunas. A opção ideal para esclarecer os princípios do método é pesquisar em uma literatura confiável, garantindo sua eficácia. É desejável que o casal seja acompanhado pelo mesmo instrutor. Isso gera vínculo e promove a adesão do casal ${ }^{(12)}$.

Algumas mulheres reconhecem que quando o método faIha a causa é comportamental, pois, conscientemente, tiveram relações em períodos e assim engravidaram.

Sim, engravidei. Não porque o método não funcionasse, mas é porque eu fugi da regra e permiti que isso acontecesse... (E2)

Gostaria de enfatizar que eu engravidei realizando o método (...) Não foi por falha do método, mas por falha pessoal 
minha, por não procurar uma orientação adequada. (E8)

Além das falhas comportamentais, algumas mulheres se culpam por não ter buscado orientações corretas sobre o método. Este reconhecimento de falha pessoal é primordial. Caso contrário, as usuárias podem cair no que diz o senso comum sobre a falsa ineficácia e insegurança do método Billings. No entanto, vencidas as etapas iniciais do processo, observamos que quando a mulher é bem instruída e acompanhada por um profissional, com o passar do tempo e com a experiência, ela adquire confiança e certifica-se de sua eficácia como um método contraceptivo.

Indico, e hoje, ensino gratuitamente, pra mulheres que querem aprender, porque confio nesse método, e para minha vida foi uma ótima escolha. (E9)

Quando comecei a fazer o método, foi uma experiência, porque queria saber se era eficaz, e hoje falo com convicção que se respeitado as regras impostas pelo método, e se observando, qualquer mulher pode fazê-lo, pode conseguir uma gravidez, ou evitar, sem nenhum dispositivo químico ou de barreira (...) a consciência, e o conhecimento tira todo o medo. (E10)

O tempo de prática, a correção dos erros iniciais e o conhecimento da técnica transmitem confiança às mulheres, e elas passam a recomendar e ensinar o Billings a outras pessoas. Assim o comportamento muda, as atitudes frente às regras são respeitadas. O medo dá lugar à convicção, a insegurança abre espaço para a segurança. Neste momento, o método passa a ser uma ótima escolha para a vida reprodutiva da mulher, respeitando as individualidades e as peculiaridades de cada ser.

\section{CONSIDERAÇÕES FINAIS}

No conjunto das percepções foi possível compreender a vivência da mulher que utiliza o Método da Ovulação Billings. O conhecimento da própria fertilidade, o sentimento durante a sua realização, trazem inúmeros benefícios para a mulher, e para o casal, além de não apresentar efeitos secundários, nem complicações decorrentes do seu uso.

Apesar da efetividade do MOB, ser demonstrada por vários estudos, e aplicada em diversos países, sua utilização e divulgação é pouco difundida. Isso reflete, possivelmente, a ausência de divulgação dos métodos naturais de planejamento familiar, tanto pelos órgãos governamentais como pelos próprios profissionais da saúde, não sendo clara a razão de tal desinteresse.

Na opção pelo MOB, a religião/crença, foi citada como fatores principais para nortear a escolha do método contraceptivo, demonstrando que além do bem-estar físico, as muIheres buscam um método que lhe garantam um bem-estar psico-espiritual, que seja aceito pela denominação religiosa ao qual fazem parte, pois se sentem satisfeitas quando estão em sintonia, cumprindo os preceitos daquilo que acreditam. A naturalidade do método também foi citada como fator de escolha, pois tomar posse de sua própria fecundidade, sem afetar o funcionamento do seu corpo, leva ao aumento da auto-imagem, tranquilidade e sensação prazerosa do controle do próprio corpo, sem sujeitar-se ao outro.

Algumas mulheres nas entrevistas citam a realização do MOB por observação do muco cervical, porém não realizaram as regras corretamente, erro atribuído pela utilização do método sem consulta prévia a literatura, profissional de saúde ou instrutora experiente. Um outro grupo realiza corretamente o MOB conforme descrição de seus descobridores, relatam que procuraram ajuda a pessoas experientes, e recorreram a literatura, antes do início da realização, cada uma com descrição de realização usando de sua própria linguagem e singularidade nessa definição, flexibilidade permitida pelo MOB, onde a mulher diante da descoberta de sua fertilidade, com suas próprias palavras define, seu padrão básico de fertilidade, seu dia ápice, e seus dias após morte ovular, mas estruturada pela pesquisa científica já realizada. Quando a regra do método Billings é reconhecida e aplicada corretamente, este conhecimento proporciona para as usuárias inúmeras vantagens físicas e psíquicas, conforme relatos nas entrevistas, e todas as entrevistadas recomendam o uso do método.

Acredita-se, portanto que é necessário contar com profissionais capacitados, a fim de oferecer informações e acompanhamentos de qualidade, aos que tiverem interesse pelo MOB, orientando sobre seus benefícios e limitações, garantindo uma prática correta. Isso provavelmente aumentará a confiança da população no método, e por consequência, o número de usuários em um método, já comprovado por pesquisas em diversos países e certificado pela OMS, que é seguro, natural e eficaz.

\section{REFERÊNCIAS}

1. Ranke-heinemann U. Eunucos pelo reino de Deus. 3. ed. Rio de Janeiro: Rosas dos Tempos; 1996.

2. Zanconato G, Zighelboim, I, Ros A. Anticoncepción: princípios científicos e práticos. BEMFAM: Gráfica Europa; 1988.

3. Lopes OC. A medicina no tempo. São Paulo: Melhoramentos; 1970.

4. Kaufman MA, Rondinelli IM. Manual de treinamento em planejamento familiar para enfermeiros. Rio de janeiro: ABEPF; 1989.

5. Brasil. Constituição(1988). Constituição da Republica Federativa do Brasil. Brasília, DF: Senado Federal; 1991. p. 125.

6. Associação de Ginecologia e Obstetrícia de Minas Gerais 
[homepage na internet]. Pílula anticoncepcional completa 50 anos [acesso em 16 mai 2010]. Disponível em: www.sogimig.org.br

7. Federação Brasileira das Associações de Ginecologia e Obstetrícia [homepage na internet]. Pílula anticoncepcional completa 50 anos: cinquentona revolucionária [acesso em 16 mai 2010]. Disponível em: www.febrasgo.org.br

8. Billings EL, Westmore A. O método Billings, controle de fertilidade sem drogas e sem dispositivos artificiais. 12 . ed. São Paulo: Paulus; 2007. p. 217-30.

9. Minayo MCS. O Desafio do Conhecimento: pesquisa qualitativa. 11. ed. São Paulo: Hucitec/Abrasco; 2008.

10. Bardin L. Análise de conteúdo. Lisboa: Edições 70; 1997.

11. Art Blog [homepage na internet]. Sexo e as religiões [acesso em 03 out 2010]. Disponível em: http://falandodesexoeartecomromeo.arteblog.com.br/24932/o-sexo-e-as-religioes/ealth system

12. Billings EL, Billings JJ, Catarinich M. Atlas Billings do método da ovulação: padrões de muco de fertilidade e de infertilidade. 5. ed. São Paulo: Santuário; 1993.

13. Martins LM, França AP D, Kimura M. Qualidade de vida de pessoas com doença crônica. Rev Latino-Am Enferm 1996;3(4):5-8

14. Marcondes WBA. A Convergência de referências na promoção da saúde. Saúde Soc 2006;13(1):5-13.

15. Machado MFAS. Integralidade, formação de saúde, educação em saúde e as propostas do SUS: uma revisão conceitual. Ciênc Saúde Coletiva 2007;2(12):335-42.

16. Comunidade Shalom Católica [homepage na internet]. Método da ovulação Billings [acesso em 03 nov 2010]. Disponível em: http://www.comshalom.org

17. Rede Saúde [homepage na internet]. Contracepção em debate [acesso em 20 set 2010]. Disponível em: < http:// www.redesaude.org.br.

18. Silva AG. Prazer sexual na vida conjugal. 2.ed. São Paulo: Paulus; 2000.

19. Freire P. Educação e mudança. 22. ed. Rio de Janeiro: Paz e Terra; 1998.

20. Queiroz MV, Jorge MS. Health education strategies and the quality of care and teaching in pediatrics: interaction, connection and trust in professional discourse. Interface Comun Saúde Educ 2006;10(19):117-30. 